\title{
Phosphorylated-Survivin at Ser81 Induced Protein Kinase A (PKA): A back loop
}

\author{
Ferry Sandra ${ }^{1,2^{*}}$, Roya Khosravi-Far ${ }^{1}$ \\ 'Department of Pathology, Harvard Medical School, Beth Israel Deaconess Medical Center, \\ Research North, 99 Brookline Ave., Boston, MA 02215, USA \\ ${ }^{2}$ Section of Oral and Maxillofacial Oncology, Faculty of Dental Science, Kyushu University, \\ 3-1-1 Maidashi, Higashi-ku, Fukuoka 812-8582, Japan \\ "Correspondence: ferrysandra@yahoo.com
}

\section{Abstract}

\section{$\mathrm{B}$}

ACKGROUND: Survivin, a bifunctional protein, acts as suppressor of apoptosis and has an essential role in mitosis. Survivin is physically phosphorylated on $\mathrm{Thr} 34$, and other important sites such as Thr117, Ser20, Thr48 and Ser81. Our previous report has shown that Ser81 of survivin plays role in cytoprotection. In order to investigate the underlying mechanism, all motifs with medium stringency were scanned. We found that site of survivin at Ser81 was correlated to PKA, which is well reported to many cell signal machineries, including cell survival. Therefore, we focused our current investigation in finding possible correlation and interaction between survivin's Ser81 site and PKA.

METHODS: Wild-type survivin (Survivin), antisense survivin (Survivin-AS), mutated-survivin and mutatedsurvivin Ser81Ala (Survivin-S81A) were constructed. Each retroviral product was produced. Some cell lysates were prepared and immunoprecipitated. For analysis, we performed immunoblotting and PKA's activity assays.

RESULTS: In our current results, phosphorylated-PKA was correlated with survivin. Infection of survivin could lead to acceleration of PKA's activityn in a viral particle dependent manner. This positive back loop induction by survivin was shown to be correlated to Ser81 site, since survivin-mediated PKA activity was not resulted by mutated form of survivin at Ser81 to nonphosphorylatable Ala (S81A).
CONCLUSIONS: Our results suggested a possible back loop of survivin to activate PKA, and Ser81 could be an important site to mediate the survivin-PKA back loop signaling. Survivin-induced activation of PKA might be related to cytoprotection.

KEYWORDS: Survivin, S81A, L929, PKA.

Indones Biomed J $2011 ; 3$ (2) : 138-142

\section{Introduction}

Survivin, an important member of Inhibitor of Apoptosis (IAP) family, has been known as a bifunctional protein that acts as suppressor of apoptosis and has an essential role in mitosis (1-6). Survivin is physically phosphorylated at Thr34 (2-4), and other important sites, such as Thr117 (3,4), Ser20 (3-5), Thr48 (6) and Ser81 (7). All these sites were reported to be important in controlling survivin's activities. Phosphorylation of survivin at Thr34 has an effect to stabilize survivin at prometaphase and metaphase against proteasomal degradation and heighten an anti-apoptotic threshold in cells traversing mitosis (3). Phosphorylation of survivin at Thr1 17 has an effect to lower its affinity for the interaction with centromeric chromatin (3). Phosphorylation of survivin at Ser20 has an effect to dissociate survivin with X-linked Inhibitor of Apoptosis (XIAP) (3-5). Phosphorylation of survivin at Thr48 has an effect to alter its binding to borealin and thereby may influence its ability to promote cell proliferation and 
inhibit cell death (6). Possible phosphorylation of survivin at Ser81 has an effect to enhance Tumor Necrosis FactorRelated Apoptosis-Inducing Ligands (TRAIL) in inducing apoptosis (7).

As a crucial integrator of multiple signaling networks, among several, cyclic AMP (cAMP)-dependent protein kinase A (PKA), a Ser/Thr kinase, is important in cell proliferation, migration and apoptosis $(5,8)$. PKA is organized as a tetrameric holoenzyme composed of 2 catalytic subunits that are maintained in an inactive conformation by 2 regulatory subunits $(\mathrm{RI} \alpha / \beta$ and $\mathrm{RII} \alpha / \beta)$ (9-12). PKA is activated in response to growth factors $(8,10-13)$, and this activity is required for growth factor-mediated cell migration, in part through the regulation of Rac activity. PKA activity has been reported to have correlation with increased cell survival via phosphorylation of $\mathrm{Bad}$, a proapoptotic member of $\mathrm{Bcl}-2$ family $(5,14)$, or in opposition, induction of apoptosis via phosphorylation of Par-4 $(5,15)$. Dissociation of survivin and XIAP caused by phosphorylation of survivin on Ser20 can disrupt cytoprotective pathway of survivin-XIAP intermolecular cooperation (5). Conversely, mitochondrial survivin or a non-PKA phosphorylatable survivin mutant binds and enhances XIAP stability, synergistically inhibits apoptosis, and accelerates tumor growth (5).

Our previous report has shown that Ser81 of survivin, plays role in cytoprotection (7). In order to explore further in the underlying mechanism, a motif scan was performed by using Scansite tools (scansite.mit.edu). In all scanned motifs with medium stringency, we found that site of survivin at Ser81 is correlated to PKA, which is well reported to many cell signal machineries, including cell survival. Therefore, we focused our current investigation in finding possible correlation and interaction between survivin's Ser81 site and PKA.

\section{Methods}

\section{Preparation of Survivin Constructs, Viral Production and L929 Cell Culture}

All preparations of Antisense survivin (Survivin-AS) and Ser81Ala mutants (Survivin-S81A) were described in our previous report (7). Similar protocols of viral production and L929 cells culture were conducted. Briefly, Antisense Survivin (Survivin-AS) were constructed with 5' $\mathrm{Hpal}$ and 3'Hpal sites. While Survivin Thr34Ala (Survivin T34A) and Ser81 Ala mutants (Survivin-S81A) with 5'Bgl II and 3'Hpal sites. cDNAs were inserted in p MSCV-IRES-GFP vector with cytomegalovirus (CMV) promoter. Each vector was transformed in DH5 $\alpha$ Escherichia coli, purified and confirmed. Each cDNA was trasnfected in BOSC 23 cells by caclium phosphate method with addition of $\mathrm{pCl} 3$ EcotR for 10 hours at $37^{\circ} \mathrm{C}$. Viruses were harvested at 72 hrs after transfection and tittered with by using NIH3T3 cells. L929 cells were cultured in $\alpha$-MEM containing $10 \%$ horse serum. Infection was carried out using viral product of BOSC 23 cells (survivin, survivin-AS, survivin-T34A, survivin-S18A or vector only) for $48 \mathrm{hrs}$.

\section{Immunoprecipitation}

Cells were collected, washed with PBS and lysed in cold lysis buffer (20 mM Tris- $\mathrm{HCl}$ (pH 8.0), $500 \mathrm{mM} \mathrm{NaCl}, 1$ mM EDTA, $1 \mathrm{mM}$ EGTA, $10 \mathrm{mM} \beta$-glycerophosphate, $10 \mathrm{mM} \mathrm{NaF}, 10 \mathrm{mM}$ pNPP, $300 \mathrm{mM} \mathrm{Na} \mathrm{VO}_{4}, 1 \mathrm{mM}$ benzamidine, $2 \mathrm{mM}$ PMSF, $10 \mathrm{mg} / \mathrm{mL}$ aprotinin, $1 \mathrm{mg} /$ $\mathrm{mL}$ leupeptin, $1 \mathrm{mg} / \mathrm{mL}$ pepstatin, $1 \mathrm{mM}$ DTT and $0.25 \%$ Nonidet $\mathrm{P}-40$ ). The supernatant was obtained by centrifugation at $12,000 \times \mathrm{g}$ for $10 \mathrm{~min}$ at $4^{\circ} \mathrm{C}$. Protein concentrations were measured using Bio-Rad protein assay. The cell lysates were immunoprecipitated with rabbit polyclonal anti-survivin (Novus Biologicals, Littleton, CO, USA) or anti-phospho-(Tyr) p85 PI3K (Cell Signaling, Beverly, MA, USA) antibody immobilized with protein $\mathrm{G}$ Sepharose, in immunoprecipitation buffer (40 mM Tris- $\mathrm{HCl}$ (pH 8.0), $500 \mathrm{mM} \mathrm{NaCl}, 1 \mathrm{mM}$ EDTA, 1 mM EGTA, $10 \mathrm{mM}$ b-glycerophosphate, $10 \mathrm{mM} \mathrm{NaF}, 10$ $\mathrm{mM}$ pNPP, $300 \mathrm{mM} \mathrm{Na} \mathrm{VO}_{4}, 1 \mathrm{mM}$ benzamidine, $2 \mathrm{mM}$ PMSF, $10 \mathrm{mg} / \mathrm{mL}$ aprotinin, $1 \mathrm{mg} / \mathrm{mL}$ leupeptin, $1 \mathrm{mg} / \mathrm{mL}$ pepstatin, $1 \mathrm{mM}$ DTT, and $0.1 \%$ Nonidet P-40).

\section{Immunoblotting}

Immunoprecipitated samples were separated by SDSpolyacrylamide gel electrophoresis (PAGE) and transferred to a polyvinylidene difluoride (PVDF) sheet. After blocking with 5\% skim milk in Tris-buffered saline (TBS, $150 \mathrm{mM} \mathrm{NaCl}$ and $50 \mathrm{mM}$ Tris- $\mathrm{HCl}, \mathrm{pH} 7.4$ ), the sheets were incubated with rabbit polyclonal anti-survivin (Novus Biologicals) or anti-phospho-(Tyr) p85 PI3K (Cell Signaling) antibody. The secondary antibody was horseradish peroxidase-conjugated donkey anti-rabbit (Amersham, Buckinghamshire, UK) antibody diluted 1:2000. The bound antibodies were visualized using the ECL system (Amersham).

\section{PKA's Activity Assay}

Cells were washed with PBS, suspended in cold extraction buffer (25 mM Tris- $\mathrm{HCl}$ ( $\mathrm{pH} 7.4$ ), $0.5 \mathrm{mM}$ EDTA, $0.5 \mathrm{mM}$ EGTA, $0.05 \%$ Triton X-100, $10 \mathrm{mM} \beta$-mercaptoethanol, 1 $\mu \mathrm{g} / \mathrm{mL}$ leupeptin, and $1 \mu \mathrm{g} / \mathrm{mL}$ aprotinin) and homogenized 
using a cold homogenizer. Then the lysate were centrifuged for $5 \mathrm{~min}$ at $14,000 \times \mathrm{g}, 4^{\circ} \mathrm{C}$, and subjected to Protein Kinase A assay kit (Calbiochem, San Diego, CA, USA). Briefly, to initiate the reaction, $5 \mu 1$ of PKA sample was added to $20 \mu \mathrm{l}$ of the PKA reaction mixture (ATP, Biotinylated Kemptide, cAMP, PKA Reaction Buffer and [32P]ATP) and incubated at $37^{\circ} \mathrm{C}$ for $30 \mathrm{~min}$. To terminate reaction, $10 \mu \mathrm{l}$ of stop solution, $3 \mu \mathrm{l}$ of $50 \%$ trichloroacetic acid and $2 \mu \mathrm{l}$ of $1 \%$ BSA were added, mixed and incubated on ice for $10 \mathrm{~min}$. After centrifugation for $5 \mathrm{~min}$ at 14,000 $\times \mathrm{g}, 25 \mu \mathrm{l}$ of supernatant were neutralized by adding 5 $\mu \mathrm{l}$ of neutralization buffer. $8 \mu \mathrm{l}$ of avidin was added to all terminated reaction samples and incubated for $5 \mathrm{~min}$ at room temperature. Sequentially transfer $50 \mu \mathrm{l}$ of wash solution plus $20 \mathrm{~mL}$ of the reaction samples into the sample reservoirs of the centrifugal ultrafiltration units. Centrifugation was done for $5 \mathrm{~min}$ at $14,000 \times \mathrm{g}$, then 100 $\mu l$ of wash solution to sample reservoir followed by another spin. This washing was repeated twice. Transfer was done to the samples containing the reaction and reference samples into vials containing scintillation cocktail. Count for radioactivity was measured with a channel set for ${ }^{32} \mathrm{P}$ for $1 \mathrm{~min}$. Calculations were done according to the protocol provided along with the kit.

\section{Results}

Binding complex of survivin and phosphorylated-PKA Figure 1A shows a positive correlation between survivin and phosphorylated-PKA in the survivin-immunoprecipitated and phospho-(Tyr) p85 PI3K-immunoblotted results, meaning that survivin-infected L929 cells (L929 Survivin) had higher amount of survivin-bound phosphorylatedPKA protein compared to L929 wild type cells (L929). A positive correlation between survivin and phosphorylatedPKA was also found, when L929 Survivin and L929 cells were immunoprecipitated with anti-phospho-(Tyr) p85 PI3K and immunoblotted with anti-survivin antibodies (Figure 1B).

\section{Survivin induced PKA activity}

The positive correlation of survivin and phosphorylatedPKA was then investigated further. L929 with infection of various viral particle concentrations were subjected to PKA's activity assay. The results showed that survivin could induce PKA activity in a survivin viral particle dependent manner (Figure 2). A high PKA activity was observed in the $\mathrm{L} 929$ cells infected with $75 \times 10^{7}$ viral particle $/ \mathrm{mL}$ retrovirus of Survivin.
B
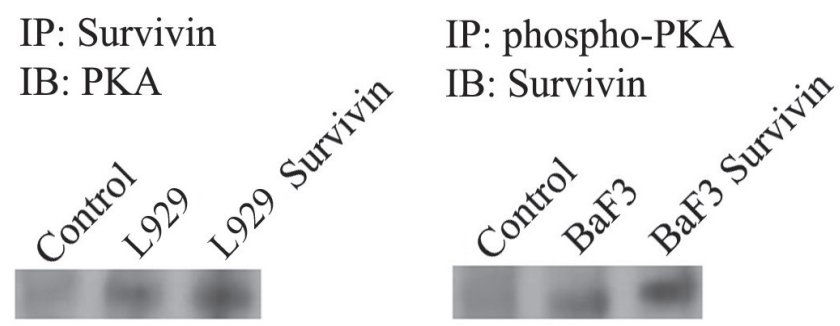

Figure 1. Binding Complex of Survivin and Phosphorylated PKA. L929 cells were infected with 75 viral particle/mL retrovirus survivin (L929 Survivin) for 48 hours, cell sorted, lysed, immunoprecipitated and immunoblotted as indicated in the panel. Beads only, without linked-antibody, were also applied as negative controls (Control). Detailed procedures were described in "Material and Methods". These experiments were repeated 3 times. IP: immunoprecipitation. IB: immunoblotting. PhosphoPKA: phosphorylated-PKA. L929: wild type (not being infected).

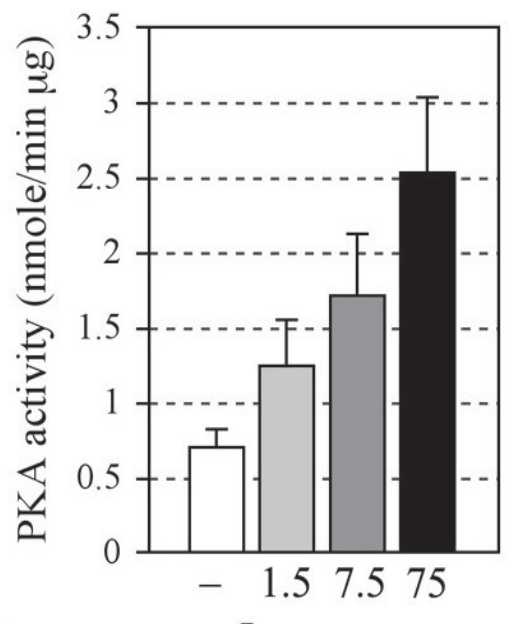

Survivin (x10 $0^{7}$ iral particle $\left./ \mathrm{ml}\right)$

Figure 2. Survivin induced PKA activity. L929 cells were infected with various viral particle concentrations of retrovirus survivin for 48 hours as indicated in the panel. All treated cells were collected and subjected to PKA's activity assay. Detailed procedures were described in "Material and Methods". These experiments were repeated 3 times.

\section{Survivin's Ser81 site was important to induce PKA activity}

Based on the motif scan bioinformatic result, site of survivin at Ser81 is correlated to PKA, therefore the mutated form of S81A was then applied to pursue the study. Based on results in Figure 2, the number of $75 \times 107$ viral particle $/ \mathrm{mL}$ retrovirus was pointed as reference. As shown in Figure 3, PKA activity of L929 Survivin was reproduced. Abolition of survivin by antisense in L929 cells (L929 Survivin-AS) 
resulted a base level of PKA activity, almost similar to the PKA activity level of wild type L929 (L929). Abolition of survivin-induced PKA activity/slight PKA activity induction was observed in L929 Survivin-S81A as well. L929 Vector (vector control) showed a closed PKA activity level to L929, showing that a survivin-dependent PKA activity was confirmed.

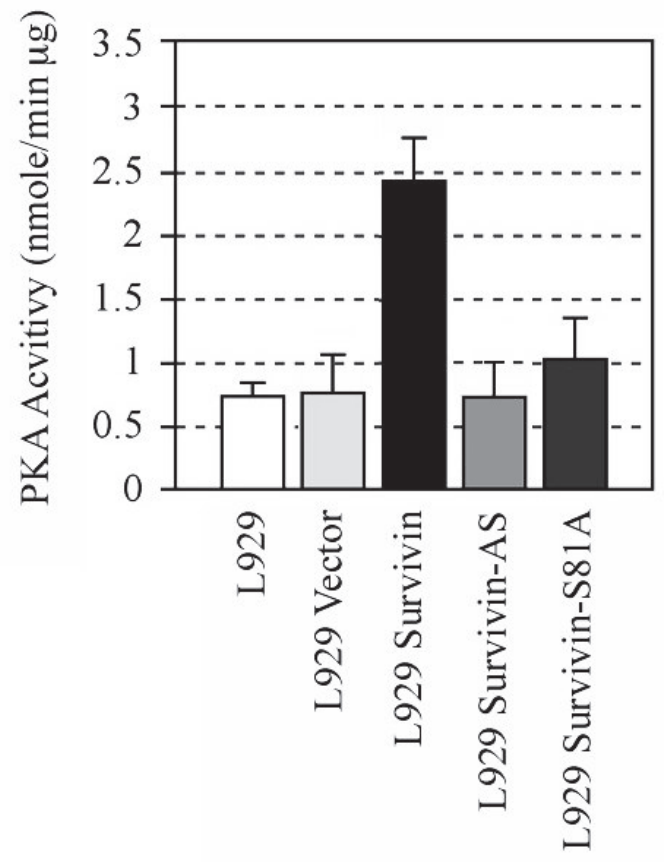

Figure 3. Survivin's Ser81 site was important to induce PKA activity. L929 cells were infected with $75 \times 10^{7}$ viral particle/ $\mathrm{mL}$ retrovirus of Survivin (L929 Survivin), Survivin-AS (L929 Survivin-AS), Survivin-S81A (L929 Survivin-S81A) or vector (L929 Vector) for 48 hours and cell sorted. All treated cells were collected and subjected to PKA's activity assay. Detailed procedures were described in "Material and Methods". These experiments were repeated 3 times. L929: wild type (not being infected).

\section{Discussion}

Our previous results have shown that mutated survivin S81A showed marked suppression on survivin's cytoprotection and enhanced TRAIL's apoptotic activity in inducing apoptosis in L929 cells (7). To pursue on the mechanism, Scan Site bioinformatic tool was used. Survivin's site at Ser81 was predicted to be correlated to PKA. It is reported that, although PKA phosphorylated survivin at Ser81 in a kinase assay, no clear phosphorylation on this residue was detected using a Ser81 phospho-specific antibody (5).
Therefore, we investigated on a possible back loop signaling of survivin to PKA. In our current results, phosphorylated-PKA was correlated with survivin. In addition, infection of survivin could lead to acceleration of PKA's activity. Back loop as a pathway of signaling, has been widely reported, including pathways related to IAPs (16) and protein kinases (17-18). IAPs have been shown to be induced by NF- $\kappa \mathrm{B}$ or $\mathrm{v}$-Rel in multiple cell lines and conversely, human IAP (HIAP) 1 and HIAP2 have been shown to activate NF- $\kappa \mathrm{B}$ possibly forming a positive feed-back loop (16). Another example, merlin exerts its growth suppressive activity by inhibiting p21activated kinase (PAK), PKA and Akt through binding to PI3K enhancer longer isoform (PIKE-L) (17). However, in the opposite, merlin can be phosphorylated by Akt at Thr230/Ser315 and by PAK and PKA at Ser518, so that repressive activity of merlin can be abrogated/regulated (17).

A positive back loop induction by survivin was shown correlated to Ser81 site, since survivin-mediated PKA activity was not resulted by mutated form of survivin at Ser81 to nonphosphorylatable Ala (S81A). PKA activity has been reported to have correlation with increased cell survival via phosphorylation of $\mathrm{Bad}$, a proapoptotic member of Bcl-2 family $(5,14)$. Phosphorylation of Bad at Ser 155 by PKA in vitro and is the only residue in $\mathrm{Bad}$ that becomes phosphorylated when cells are exposed to PKA-elevating agents (19). The phosphorylation of Bad at Ser 155 prevents it from binding to $\mathrm{Bcl}-\mathrm{X}_{\mathrm{L}}$ and promotes its interaction with 14-3-3 proteins (19).

Despite regulating $\mathrm{Bad}$, during platelet-derived growth factor(PDGF)-induced chemotaxis, PKA promotes membrane ruffling by regulating phosphatidylinositol 3,4,5-trisphosphate (PIP3) dynamics (8). PKA inhibition caused a marked attenuation in the bulk accumulation of PIP3 following PDGF stimulation, without effects on PI3K activity (8). The deficits in PIP3 dynamics correlated with a significant inhibition of growth factor-induced membrane recruitment of endogenous Akt and Rac activation in PKA-inhibited cells (8). In addition, PKAactivating agents inhibited the NF- $\kappa \mathrm{B}$-dependent reporter gene expression, blocked the interaction of PKA catalytic subunit and p65 subunit of NF- $\kappa \mathrm{B}$, and attenuated PKAdependent phosphorylation of p65 at Ser276 (20). All these PKA signaling pathways are potential to provide cytoprotection, hence, further investigation should be pursued on the possible survivin-mediated PKA signal transduction. Taken together, our current results suggested a possible back loop of survivin to activate PKA, and Ser81 could be an important site to mediate the survivinPKA back loop signaling, hence leading to further survival signalling pathways. 


\section{Acknowledgement:}

We thank Aristi Papaioannou for the lab assistance.

\section{References:}

1. Colnaghi R, Connel CM, Barret RMA, Wheatley SP. Separating the Anti-apoptotic and Mitotic Roles of Survivin. J Biol Chem 2006; 281: 33450-6.

2. Aspe JR, Wall NR. Survivin-T34A: molecular mechanism and therapeutic potential. Onco Targets Ther 2010; 3: 247-54.

3. Altieri DC. New wirings in the surviving networks. Oncogene 2008; 27: 6276-84.

4. Altieri DC. Survivin and IAP protein in cell-death mechanisms. Biochem J 2010; 430: 199-205.

5. Dohi T, Xia F, Altieri DC. Compartmentalized phosphorylation of IAP by Protein Kinase A regulates cytoprotection. Mol Cell 2007; 27: 17-28.

6. Barrett RMA, Colnaghi R, Wheatley SP. Threonine 48 in the BIR domain of survivin is critical to its mitotic and anti-apoptotic activities and can be phosphorylated by CK2 in vitro. Cell Cycle 2011; 10: 538-48.

7. Sandra F, Khosravi-Far R. Survivin S81A Enhanced TRAIL's Activity in Inducing Apoptosis. Indones Biomed J 2010; 2: 113-7.

8. Deming PB, Campbell SL, Baldor LC, Howe AK. Protein Kinase A regulates 3-Phosphatidylinositide dynamics during Platelet-derived Growth Factor-induced membrane ruffling and chemotaxis. J Biol Chem 2008; 283: 35199-211.

9. Taylor SS, Yang J, Wu J, Haste NM, Radzio-Andzelm E, Anand G. PKA: a portrait of protein kinase dynamics. Biochim Biophys Acta 2004; 1697: 259-69.

10. Tasken K, Aandahl EM. Localized effects of CAMP mediated by distinct routes of protein kinase A. Physiol Rev 2004; 84: 137-67.
11. Kirschner LS, Yin Z, Jones GN, Mahoney E. Mouse models of altered protein kinase A signaling. Endocr Relat Cancer 2009;16: 773-93.

12. Taylor SS, Kim S, Cheng CY, Brown SH, Wu J, Kannan N. Signaling through CAMP and CAMP-dependent Protein Kinase: Diverse Strategies for Drug Design. Biochim Biophys Acta 2008; 1784: 16-26.

13. deBlaquiere J, Walker F, Michelangeli VF, Fabri L, Burgess AW. Platelet-derived growth factor stimulates the release of protein kinase A from the cell membrane. J Biol Chem 1994; 269: 4812-8.

14. Harada H, Becknell B, Wilm M, Mann M, Huang LJ, Taylor $\mathrm{SS}$, et al. Phosphorylation and inactivation of BAD by mitochondria-anchored protein kinase A. Mol Cell 1999; 3: 413-22.

15. Gurumurthy S, Goswami A, Vasudevan KM, Rangnekar VM. Phosphorylation of Par-4 by protein kinase $\mathrm{A}$ is critical for apoptosis. Mol Cell Biol 2005; 25: 1146-61.

16. LaCasse EC, Baird S, Komeluk RG, MacKenzie AE. The inhibitors of apoptosis (IAPs) and their emerging role in cancer. Oncogene 1998; 17: 3247-59.

17. Ye K. Phosphorylation of merlin regulates its stability and tumor suppressive activity. Cell Adh Migr 2007; 1: 196-8.

18. Jurek A, Amagasaki $\mathrm{K}$, Gembarska A, Heldin $\mathrm{CH}$, Lennartsson J. Negative and positive regulation of MAPK phosphatase 3 controls platelet-derived growth factor-induced Erk activation. J Biol Chem 2009; 284: 4626-34.

19. Lizcano JM, Morrice N, Cohen P. Regulation of BAD by cAMPdependent protein kinase is mediated via phosphorylation of a novel site, Ser155. Biochem J 2000; 349: 547-57.

20. Gao N, Hibi Y, Cueno M, Asamitsu K, Okamoto T. A-kinaseinteracting Protein 1 (AKIP1) Acts as a Molecular Determinant of PKA in NF-kB Signaling. J Biol Chem 2010; 285: 28097-104. 